Article

\title{
Grafting cv. Grechetto Gentile Vines to New M4 Rootstock Improves Leaf Gas Exchange and Water Status as Compared to Commercial 1103P Rootstock
}

\author{
Tommaso Frioni *(D), Arianna Biagioni, Cecilia Squeri, Sergio Tombesi, Matteo Gatti ${ }^{(D)}$ and \\ Stefano Poni \\ Department of Sustainable Crop Production, Università Cattolica del Sacro Cuore, Via Emilia Parmense 84, \\ 29122 Piacenza, Italy; arianna.biagioni.87@gmail.com (A.B.); cecilia.squeri@unicatt.it (C.S.); \\ sergio.tombesi@unicatt.it (S.T.); matteo.gatti@unicatt.it (M.G.); stefano.poni@unicatt.it (S.P.) \\ * Correspondence: tommaso.frioni@unicatt.it; Tel.: +39-0523-599-267
}

Received: 30 March 2020; Accepted: 13 May 2020; Published: 15 May 2020

\begin{abstract}
M4 is a relatively new rootstock that was selected for increased resilience of vineyards across hot regions where meteorological drought is often coupled to water scarcity. However, M4 has thus far been tested only against water-stress sensitive rootstocks. Against this backdrop, the aim of the present work is to examine the water status and gas exchange performances of vines grafted to M4 in comparison to those of vines grafted to a commercial stock that is drought-tolerant, 1103 Paulsen (1103P), under a progressive water deficit followed by re-watering. This study was undertaken on Grechetto Gentile, a cultivar that is renowned for its rather conservative water use (near-isohydric behavior). While fifty percent of both grafts were fully irrigated (WW), the remaining underwent progressive water stress by means of suspending irrigation (WS). Soil and leaf water status, as well as leaf gas exchanges, along with chlorophyll fluorescence, were followed daily from 1 day pre-stress (DOY 176) until re-watering (DOY 184). Final leaf area per vine, divided in main and lateral contribution, was also assessed. While 1103P grafted vines manifested higher water use under WW conditions, progressive stress evidenced a faster water depletion by 1103P, which also maintained slightly more negative midday leaf water potential $\left(\Psi_{\text {leaf }}\right)$ as compared to M4 grafted plants. Daily gas exchange readings, as well as diurnal assessment performed at the peak of stress (DOY 183), also showed increased leaf assimilation rates (A) and water use efficiency (WUE) in vines grafted on M4, which were also less susceptible to photosynthetic downregulation. Dynamic of stomatal closure targeted at $90 \%$ reduction of leaf stomatal conductance showed a similar behavior among rootstocks since the above threshold was reached by both at $\Psi_{\text {leaf }}$ of about $-1.11 \mathrm{MPa}$. The same fractional reduction in leaf A was reached by vines grafted on M4 at a $\Psi_{\text {leaf }}$ of $-1.28 \mathrm{MPa}$ vs. $-1.10 \mathrm{MPa}$ measured in 1103P, meaning that using M4 as a rootstock will postpone full stomatal closure. While mechanisms involved in improved $\mathrm{CO}_{2}$ uptake in M4-grafted vines under moderate-to-severe stress are still unclear, our data support the hypothesis that M4 might outscore the performance of a commercial drought-tolerant genotype (1103P) and can be profitably used as a tool to improve the resilience of vines to summer drought.
\end{abstract}

Keywords: transpiration; drought; water stress; Vitis vinifera L.; stomatal closure; rootstock; water use efficiency

\section{Introduction}

Global warming is making rapid and transformative changes in the traits associated with viticulture across the world [1]. The majority of Mediterranean wine regions are known to confront 
very hot summers and mild winters, with peak temperatures often surpassing the threshold of $40{ }^{\circ} \mathrm{C}$ in the growing season [1-5]. The heightened severity and frequency of several summer-induced stresses exerted in the vineyard are one of the most common ramifications of warming trends [1]. They encompass the simultaneous emergence of heat and water stress in conjunction with excessive radiation loads, thus leading to necrosis and leaf photoinhibitions, a significant reduction in yields, spoilage of fruit quality, and, particularly in young plantings, vineyard loss $[1,6]$.

Indubitably, adopting a drought-resistant rootstock denotes a fundamental choice of establishing a new vineyard when dealing with sites characterized by water scarcity. Even though rootstock breeding, as well as selection programs, have witnessed slow progress in viticulture, as evidenced in a subdued rate of material released over the past century, the pressure associated with warming trends has resulted in the selection of genotypes that can possibly confer to the scion a higher tolerance to abiotic stresses. It is notable that the M4 rootstock ((Vitis vinifera $\times$ Vitis berlandieri) $\times$ Vitis berlandieri cv. Resseguier n.1) has recently been recognized as a promising material to establish vineyards in areas that are vulnerable to summer-related droughts. In that context, Meggio et al. [7] delineated some physiological attributes of own-rooted M4 vines impacted by water deficit, observing that the physiological performances of the new genotype were better as compared to own-rooted 101-14 Millardet et De Grasset (Vitis riparia $\times$ Vitis rupestris) vines, operating at $30 \%$ of field capacity. In addition, M4 demonstrated accelerated recovery upon re-watering [7]. According to Galbignani et al. [8], Sangiovese vines grafted to M4 exhibit a slower response to water-stress with regard to deferred pre-dawn water potential as well as whole canopy assimilation drop in comparison to the vines grafted onto $\mathrm{SO} 4$ (Vitis berlandieri $\times$ Vitis riparia), which is particularly vulnerable to drought. Moreover, it was observed that the hydraulic conductance rates of M4 were higher than SO4 [8]. Similarly, while undertaking a comparison of the same rootstock/scion combinations, Merli et al. [9] demonstrated that Sangiovese grafted onto M4 was able to maintain a higher whole canopy water use efficiency under water stress.

Meanwhile, other studies have directed their attention on M4 rootstock metabolomic, transcriptomic, or proteomic profiling. In an exhaustive transcriptomic evaluation of M4 and 101.14 Millardet et De Grasset roots, Corso et al. [10] observed that heightened drought tolerance demonstrated by M4 pertained to different modulations amidst water-stress conditions associated with the phenil-propanoid pathway. Correspondingly, while making a comparison between the metabolic and proteomic profile of the two same rootstocks under water stress conditions, Prinsi et al. [11] highlighted the M4 downregulation of heat shock proteins and abscisic acid linked with the upregulation of metabolites that are osmotically active.

Despite compelling evidence of the positive impacts ascribed to M4 rootstock on the scion's water status even under extreme water paucity, extant literature provides little information concerning M4 behavior in comparison to other rootstocks that are classified as "drought-tolerant." As a matter of fact, M4 has primarily been tested in comparison to SO4 [8,9] and 101-14 Millardet et De Grasset [7,10,11], two conventional rootstocks that are known to display poor tolerance to water shortage [12,13]. In hot or arid conditions, vineyards are typically known to adopt drought-tolerant and robust rootstocks (Vitis berlandieri $\times$ Vitis rupestris) whose performance is good in forming tap roots that are capable of digging water from deep soil layers, including 110 Richter, 1103 Paulsen, or 140 Ruggeri [12-15]; for this reason, increasing more hints about directly comparing these rootstocks with M4 would also help facilitate the assessment of marginal gain achieved after the selection of M4. In extant literature [16], only one paper was able to offer data about a Vitis vinifera cultivar (Cabernet Sauvignon) that was grafted to M4 as well as to a rootstock that was drought tolerant (namely, 1103 Paulsen), thus suggesting that M4 was able to better sustain berry growth and expedited ripening. Unfortunately, this study excluded any irrigation management, soil water content, or data concerning the status of plant water or physiological parameters.

Introduction of the iso/anisohydry nomenclature to categorize Vitis vinifera L. varieties dates back to the work by Berger-Landefeldt [17]; since then, several definitions for the two categories have been proposed. Those attributing to isohydric plants the capacity to maintain a relatively constant 
leaf water potential ( $\left.\Psi_{\text {leaf }}\right)$ despite changes in soil water potential $\left(\Psi_{\text {soil }}\right)$ and vapor pressure deficit (VPD), and ascribing to anisohydric plants the property lo let $\Psi_{\text {leaf }}$ to co-vary more strongly with $\Psi_{\text {soil }}$ and VPD, are the most shared. However, with additional information involving a larger number of varieties, growing conditions (i.e., pot vs. open field) and type of water stress (fast according to a dry-down mode or slow as it might occur in the field under progressive soil drying) led to the general opinion that relative iso/anisohydry is not a dichotomy, rather yet a continuum. In other words, there is considerable variation in water status regulation between the two extremes, and environmental conditions play an important role in affecting such variations. Against the theory of considering iso/anisohydry as a "simple" plant trait, some authors $[18,19]$ have even suggested abandoning the concept while hinting to a safer wording such as vulnerable/tolerant genotypes. Yet, the debate does not seem to be exhausted as Ratzmann et al. [20] have recently countered that iso/anisohydry is still a useful concept, suggesting that the leaf turgor loss point can be a reliable proxy to integrate the complex interactions between plant hydraulic traits. [21-28]. According to the limited information available, Grechetto Gentile stands for a near-isohydric behavior, and M4 rootstock has thus far only been tested on near-anisohydric scions $[8,9,16,29]$.

In this context, this study specifically aims at attaining the following objectives: (a) determine if grafting cv. Grechetto Gentile vine on M4 significantly alters leaf gas exchange and water status vs. 1109 grafted vines during a dry down period followed by re-watering; (b) infer mechanisms that eventually drive different vine performance, according to the used rootstock.

\section{Materials and Methods}

\subsection{Plant Material and Treatment Layout}

The experiment was carried out in the year 2018 in the Italian city of Piacenza ( $\left.44^{\circ} 55^{\prime} \mathrm{N}, 9^{\circ} 44^{\prime} \mathrm{E}\right)$ on 20 two-year-old Grechetto Gentile (Vitis vinifera L.) vines (clone VCR433) grown outdoors in 551 pots. These pots were filled with a blend of peat and loamy soil (20:80 by volume). All vines were fertilized on two occasions (that is, one week prior to and two weeks following the bud-break) with 4 grams of Greenplant $15(\mathrm{~N})+5\left(\mathrm{P}_{2} \mathrm{O}_{5}\right)+25\left(\mathrm{~K}_{2} \mathrm{O}\right)+2(\mathrm{MgO})+$ micro. Ten vines each were grafted to 1103 Paulsen rootstock (1103P) and to M4, respectively. After somewhat weak growth recorded during the first year, in winter, each vine was pruned back to one spur with two count nodes. In May, shoot number per vine was standardized by retaining only the two most vertical and robust shoots. Vines were arranged on a vertical shoot, positioned in a $35^{\circ} \mathrm{NE}-\mathrm{SW}$ oriented row, besides being hedgerow-trained with as many as three upper foliage wires for a canopy wall that extended above the graft-union by around $1.8 \mathrm{~m}$. Then, the 20 vines were assigned randomly to four treatments in accordance with the water regime and the rootstock: 1103 Paulsen well-watered (1103P-WW), M4 well-watered (M4-WW), 1103 Paulsen water-stressed (1103P-WS), and M4 water-stressed (M4-WS). Before the commencement of this trial, pots were painted in white in order to curtail overheating induced by radiation.

All the vines were well-watered until DOY 176 (25 June) through the supply of a daily quantity of $6 \mathrm{~L}$ in separate fractions at 8:00, 12:00,15:00, and 18:00. Water stress was imposed only once vines

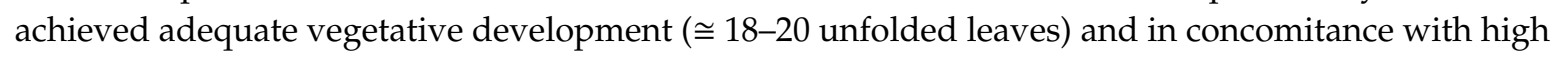
air temperatures and vapor pressure deficit (VPD). Irrigation was withheld in all WS vines until DOY 183 at 18:00 from DOY 177 at 8:00; after that, WS vines were re-watered and complete water supply was maintained for all vines throughout the remainder of the season. During water stress, the pot surface of WS and WW vines was covered using a plastic sheet for preventing infiltration and minimizing losses incurred due to soil evaporation. Shoot trimming was performed on DOY 186 by removing the apical portion of shoots outgrowing $20 \mathrm{~cm}$ beyond the top foliage wire.

Daily mean climatic data were derived by a weather station situated in close proximity to the outdoor area, recording hourly rainfall air temperature (T), and relative humidity (RH). 


\subsection{Gas Exchange Parameters and Chlorophyll Fluorescence}

Measurements of leaf gas exchange were recorded daily during the experiment from DOY 176 till DOY 184. More specifically, these readings were undertaken on a mid-shoot mature leaf per vine (five leaves per treatment) under saturating light conditions (PAR $>1400 \mathrm{mmol} \mathrm{m}^{-2} \mathrm{~s}^{-1}$ ) between 12:00 and 13:00 through the utilization of a portable gas exchange LCi infrared gas analyzer (ADC Bio Scientific Ltd., Hertz, UK). Notably, this system was equipped using a wide leaf chamber, having a $6.25 \mathrm{~cm}^{2}$ window. Additionally, all measurements were performed at ambient relative humidity with the adjustment of airflow to $350 \mathrm{~mL} \mathrm{~min}^{-1}$. Additionally, gas exchanges were measured at 8:00 on DOY 183 and 184, when daytime air temperatures were the lowest, as well as at 18:00, the time the most stressful hours of the afternoon had ended. The calculation of transpiration rate (E), leaf assimilation rate (A), as well as stomatal conductance $\left(\mathrm{g}_{\mathrm{s}}\right)$, was made from concentrations of inlet and outlet $\mathrm{CO}_{2}$ and $\mathrm{H}_{2} \mathrm{O}$. The calculation of instantaneous leaf water use efficiency (WUE leaf) was made the ratio between leaf $A$ and leaf E. Percentage loss (PL) of leaf A (PL leaf A) and leaf $g_{s}$ (PL leaf $g_{s}$ ) in M4-WS and 1103P-WS was calculated as the daily $\%$ difference in leaf $A$ as well as leaf $g_{s} v s$. the respective WW treatments.

Measurements of chlorophyll fluorescence were conducted on the leaves that were sampled via the field-portable pulse-modulated fluorimeter Handy-PEA (Hansatech Instruments, Norfolk, UK). Segments of leaves were dark-adapted for a period of $30 \mathrm{~min}$ via the use of leaf-clips supplied with the instrument. Meanwhile, the fiber optic, as well as its adaptor, were attached to a ring that was situated over the leaf-clip at around $1 \mathrm{~cm}$ from the sample, after which varied light pulses were implemented after ensuring compliance with standard routines premised on the user manual's recommendations.

\subsection{Leaf Water Status and Vine Leaf Area}

Seasonal progression of water stress was monitored on a daily basis from DOY 177 to 184 through the measurement of leaf pre-dawn water potential $\left(\Psi_{p d}\right)$ prior to sunrise (one leaf per vine; three vines per treatment), along with midday leaf water potential ( $\left.\Psi_{\text {leaf }}\right)$ at 13:00. Additionally, the midday stem water potential ( $\Psi_{\text {stem }}$ ) on DOY 183 and 184 was measured at the following timings: prior to sunrise, at 8:00, at 13:00, and at 18:00 (one leaf per vine; three vines per treatment). The measurement of $\Psi_{p d}$, $\Psi_{\text {stem, }}$ and $\Psi_{\text {leaf }}$ was done on well-exposed and mature basal-medium leaves via a Scholander pressure chamber [30].

The estimation of the vine leaf area was made at the end of the trial. The leaves that were inserted at nodes 3, 6, 9, 12, and 15 of one shoot per vine were gathered on DOY 186, in conjunction with two corresponding leaves of a lateral that developed below the trimming cut. Each leaf's area was measured using an LI-3000A leaf area meter (LI-COR Biosciences, Lincoln, NE, USA). Following the leaf fall, the total number of nodes for each cane, as well as for all lateral shoots, were ascertained. Subsequently, an estimation of the final vine leaf area was made from the primary as well as lateral shoots based on node counts and leaf-blade areas.

\subsection{Statistical Analysis}

A one-way analysis of variance (ANOVA) was undertaken in this study. Additionally, the Student-Newman-Keuls (SNK) test performed the mean separation at $p<0.05$, in case of the significance of the F-test. Over time, the data acquired for $\Psi_{\text {stem, }} \Psi_{\mathrm{pd}}$, leaf E, leaf A, $\mathrm{F}_{\mathrm{v}} / \mathrm{F}_{\mathrm{m}}$, leaf $\mathrm{g}_{\mathrm{s}}$, as well as $\mathrm{WUE}_{\text {leaf }}$ (denoted as $\mathrm{A} / \mathrm{E}$ ), were assessed using the repeated measure ANOVA routine that forms part of the XLSTAT software package. Mauchly's sphericity test was utilized for assessing the equality of variances of the differences between all possible pairs of within-subject conditions.

The existing correlations between variables were examined by means of regression analysis through SigmaPlot 11 (Systat Software Inc., San Jose, CA, USA). 


\section{Results}

\subsection{Weather Trends During the Experiment}

The experiment was carried out over a period of fairly steady weather conditions (Figure S1). Maximum daily $\mathrm{T}$ increased from $27.2^{\circ} \mathrm{C}$, recorded at the commencement of the experiment, to $34.2^{\circ} \mathrm{C}$ recorded on DOY 181 at 16:00. Subsequently, there was a decline in maximum $\mathrm{T}$ while still remaining over $30^{\circ} \mathrm{C}$ until the experiment ended. A similar pattern was followed by minimum temperatures, recording the highest value during the morning of DOY $182\left(23.1^{\circ} \mathrm{C}\right)$. No rain was recorded during WS progression, whereas $6.2 \mathrm{~mm}$ of rain was recorded on the evening of the first day after re-watering (DOY 184). Air vapor pressure deficit (VPD) at midday varied from $1.8 \mathrm{KPa}$ recorded on DOY 176 to $4.1 \mathrm{KPa}$ on DOY 181. Thereafter VPD remained steady at close to about $2.8 \mathrm{KPa}$ until the end of the experiment.

\subsection{Effects of Rootstock on Leaf Water Status and Gas Exchanges}

The rootstock was not found to impact $\Psi_{\mathrm{pd}}$ of WW vines, ranging throughout this experiment from -0.1 to $-0.3 \mathrm{MPa}$ in $1103 \mathrm{P}$ and M4 (Figure 1a). No difference was observed between treatments from DOY 177 to 180 in WS vines, whereas M4-WS vines maintained higher $\Psi_{\mathrm{pd}}$ than $1103 \mathrm{P}$ vines $(+0.17$ and $+0.09 \mathrm{MPa}$, respectively) on DOY 182 and 183. All treatments were found to recover at around $-0.2 \mathrm{MPa}$ after re-watering.

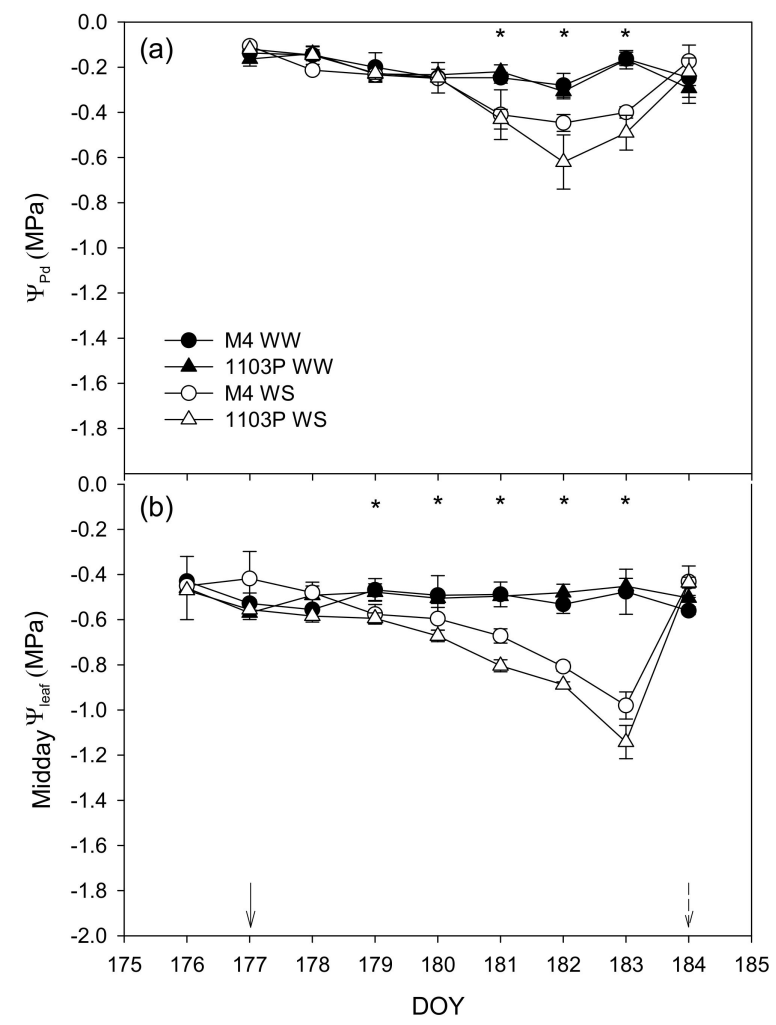

Figure 1. Trends for pre-dawn water potential ( $\Psi_{\mathrm{pd}}$, panel a) and midday leaf water potential ( $\Psi_{\text {leaf }}$, panel b) of vines cv. Grechetto Gentile grafted to M4 and 1103 Paulsen. M4-WW = well-watered vines grafted to M4; 1103P-WW = well-watered vines grafted to 1103 Paulsen; M4-WS = water-stressed vines grafted to M4; 1103P-WS = water-stressed vines grafted to 1103 Paulsen; DOY = day of the year. Bars represent standard errors $(n=3)$. Asterisk indicates dates within which significant differences among treatments were found, according to the Student-Newman-Keuls (SNK) test $(p<0.05)$. Solid arrow indicates date of imposition of WS; dashed arrow indicates date of re-watering. 
A similar pattern was followed by midday $\Psi_{\text {leaf }}$ (Figure 1b). From DOY 176 to 178 , all treatments were found to range between -0.40 and $-0.55 \mathrm{MPa}$. On DOY 180, 1103P-WS showed a significant midday $\Psi_{\text {leaf }}$ decrease (to $-0.68 \mathrm{MPa}$ ), while M4-WS maintained values that were comparable to WW vines $(-0.55 \mathrm{MPa})$. Commencing from DOY 181, midday $\Psi_{\text {leaf }}$ of M4-WS also began witnessing a drop, despite retaining higher values than 1103P-WS (+0.13 MPa). It was on the last day of stress that the difference between WS treatments peaked (-0.98MPa in M4-WS; -1.14MPa in 1103P-WS), while all vines leveled off at about $-0.5 \mathrm{MPa}$ upon re-watering.

In WW vines, grafting on 1103P resulted in a typically higher leaf A (Figure 2a) and leaf $\mathrm{E}$ (Figure 2b) in comparison to M4, despite the fact that this difference was statistically significant only at some dates (e.g., peaking on DOY 183, when it was observed that $1103 \mathrm{P}$ WW had $+25 \%$ leaf A versus M4-WW). WS started affecting photosynthesis from DOY 180, when 1103P-WS vines showed significantly lower leaf A than 1103P-WW (-49\%). Conversely, A rates recorded in M4-WW and M4-WS vines remained unchanged on the same day and the following day (DOY 181). On DOY 182, M4-WS showed much lower A than M4-WW $\left(-8.4 \mu \mathrm{mol} \mathrm{m}^{-2} \mathrm{~s}^{-1}\right)$, yet still significantly higher than 1103P-WS $\left(+1.7 \mu \mathrm{mol} \mathrm{m}{ }^{-2} \mathrm{~s}^{-1}\right)$. This confirmation was also made on the last day of stress $\left(+1.3 \mu \mathrm{mol} \mathrm{m}^{-2} \mathrm{~s}^{-1}\right.$ in M4-WS versus 1103P-WS). Although no difference was found between 1103P-WS and M4-WS after re-watering, 1103P-WS had lower photosynthesis than 1103P-WW $(-39 \%)$, whereas no difference was found between the two M4 treatments. A similar pattern was followed by leaf E of WS vines, with no tangible differences between the treatments until DOY 180, when the two 1103P treatments separated ( $-5.1 \mathrm{mmol} \mathrm{m}^{-2} \mathrm{~s}^{-1}$ in WS). On the other hand, M4-WW and M4-WS were still found to have similar leaf E. In addition to peaking on DOY 181 (+74\% in M4), the difference between WS treatments continued to assume significance until the very last day of stress $(+51 \%)$. Unlike leaf $\mathrm{A}$, there was no difference in leaf $\mathrm{E}$ after re-watering. In addition, $\mathrm{g}_{\mathrm{s}}$ followed a similar pattern (Figure S2). Consequently, WUE leaf was not found to differ between WW treatments, while M4-WS vines were able to maintain better leaf $W^{-} E_{\text {leaf }}$ than 1103 P-WS under severe water stress $(+53 \%$ on DOY 183$)$.

Figure 3 shows the diurnal trend of gas exchange parameters and $\Psi_{\text {stem }}$ for two days. On DOY 183 , when WS was the most severe, $\Psi_{\text {stem }}$ was higher in M4-WS than 1103P-WS all day long (+0.3 MPa at 18:00; Figure 3a). M4-WS showed higher leaf A (Figure 3b) as compared to 1103P-WS at 8:00 $\left(+2.48 \mu \mathrm{mol} \mathrm{m}^{-2} \mathrm{~s}^{-1}\right)$ and 13:00, while no difference was found at 18:00. Leaf E (Figure 3c) was observed to be higher in M4-WS in comparison to 1103P-WS only at 8:00 $\left(+1.49 \mathrm{mmol} \mathrm{m}^{-2} \mathrm{~s}^{-1}\right)$.

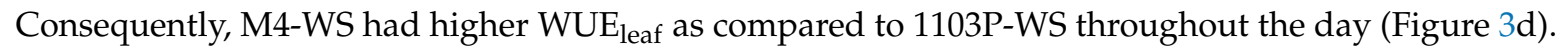
On the same day, in WW vines, 1103P exhibited higher leaf A $(+40 \%)$ and leaf E $(+37 \%)$ when compared to M4. As a result, 1103P-WW also showed higher WUE $\mathrm{E}_{\text {eaf }}$ as compared to M4-WW at 8:00 $(+0.22 \mu \mathrm{mol} / \mathrm{mmol})$ and at 13:00 $(+0.26 \mu \mathrm{mol} / \mathrm{mmol})$.

No difference was found in $\Psi_{\text {stem }}$ all day long on the first day after re-watering (DOY 184) (Figure 3e). However, WS vines were yet to exhibit a complete resumption of physiological performances at 8:00, given that they had lower leaf A (Figure 3f) and leaf E (Figure 3g) as compared to the corresponding WW vines ( $-60 \%$ leaf $A$ and $-53 \%$ leaf $E$, pooling data across both rootstocks). It is notable that the leaf A difference between M4-WW and M4-WS was merely $3.8 \mu \mathrm{mol} \mathrm{m}^{2} \mathrm{~s}^{-1}$, while that between 1103P-WW and 1103P-WS was significantly higher $\left(9.2 \mu \mathrm{mol} \mathrm{m}^{2} \mathrm{~s}^{-1}\right)$. However, there was no noted divergence at 13:00 between WS treatments, even if 1103P-WS did not reach the same leaf A of 1103P-WW, whereas the assimilation rates of M4-WS and M4-WW were comparable at 13:00 and 18:00, respectively. Taking only WW vines into consideration, $1103 \mathrm{P}$ also had higher leaf A than M4 $(+28 \%$, if pooled over the entire day) on DOY 184. In contrast, no difference was found between the treatments in $W^{-} E_{\text {leaf }}$ (Figure 3h). 


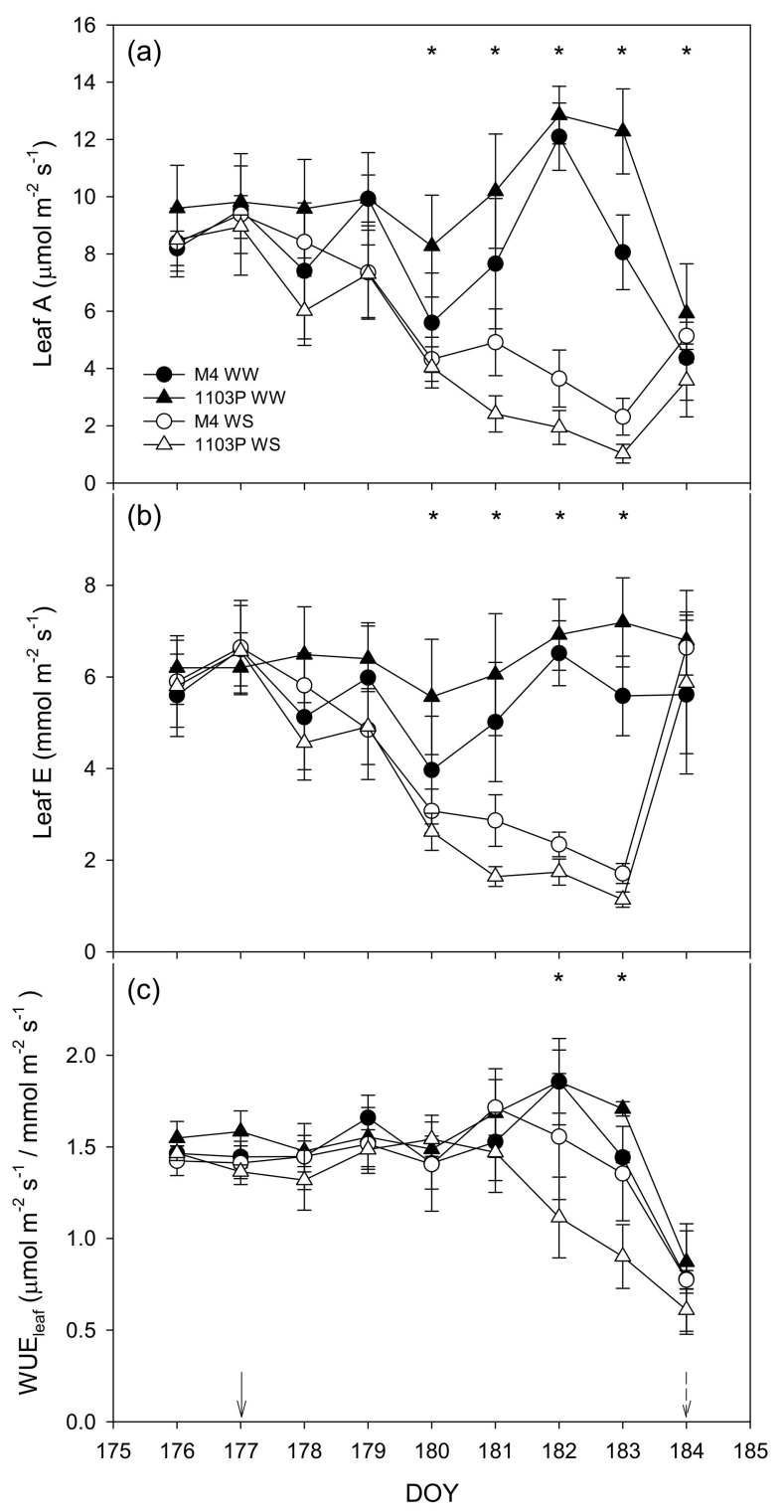

Figure 2. Trends for leaf assimilation (A, panel a), transpiration (E, panel b), and water use efficiency $\left(W_{U} E_{\text {leaf }}\right.$, panel $\mathrm{c}$ ) of vines cv. Grechetto Gentile grafted to M4 and 1103 Paulsen. M4-WW = well-watered vines grafted to M4; 1103P-WW = well-watered vines grafted to 1103 Paulsen; M4-WS = water-stressed vines grafted to M4; 1103P-WS = water-stressed vines grafted to 1103 Paulsen; DOY = day of the year. Bars represent standard errors $(n=5)$. Asterisk indicates dates within which significant differences among treatments were found according to the SNK test $(p<0.05)$. Solid arrow indicates date of imposition of WS; dashed arrow indicates date of re-watering.

To determine the $\Psi_{\text {leaf }}$ threshold at which stomatal closure (i.e., $90 \%$ reduction of $g_{s}$ ) occurred in the WS vines, fractional $g_{s}$ loss of each rootstock was regressed over $\Psi_{\text {leaf }}$ values (Figure 4a). Stomatal closure was reached at very similar $\Psi_{\text {leaf }}$ in both rootstocks (-1.11 MPa in M4 and $-1.14 \mathrm{MPa}$ in 1103P, respectively). The same analysis performed for the fractional reduction in leaf $\mathrm{A}$ led to a quite different outcome as while $90 \%$ reduced leaf A rate already occurred at $-1.10 \mathrm{MPa}$ in 1103 , the same degree of leaf A limitation was reached in M4 at a $\Psi_{\text {leaf }}$ value of $-1.29 \mathrm{MPa}$ (Figure $4 \mathrm{~b}$ ). 


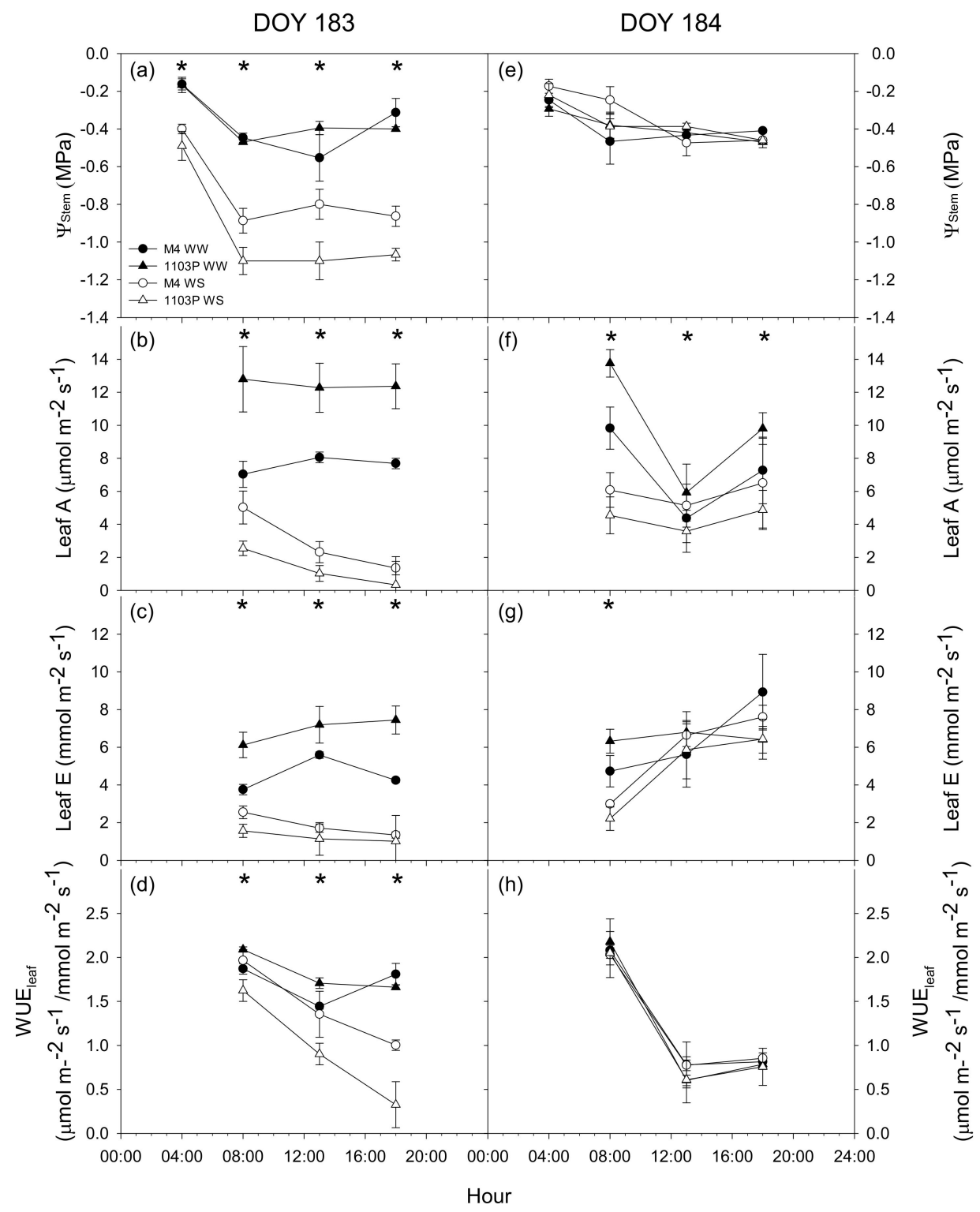

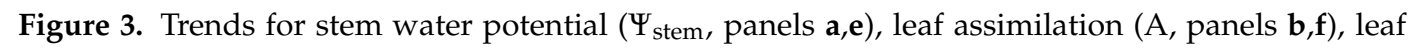
transpiration (E, panels c,g), and water use efficiency (WUEleaf, panels $\mathbf{d}, \mathbf{h}$ ) of vines cv. Grechetto Gentile grafted to M4 and 1103 Paulsen on the days of the year (DOY) 183 (panels a-d) and 184 (panels e-h). M4-WW = well-watered vines grafted to M4; 1103P-WW = well-watered vines grafted to 1103 Paulsen; M4-WS = water-stressed vines grafted to M4; 1103P-WS = water-stressed vines grafted to 1103 Paulsen; DOY $=$ day of the year. Bars represent standard errors $(n=3)$. Asterisks indicate dates within which significant differences among treatments were found, according to the SNK test $(p<0.05)$.

\subsection{Chlorophyll Fluorescence, and Vine Leaf Area}

During the progression of water stress (Figure 5), the treatments did not show different Fv/Fm despite the fact that 1103P-WS showed a significantly lower Fv/Fm (0.68) at re-watering as compared to any other treatment (0.80 in M4-WS). 


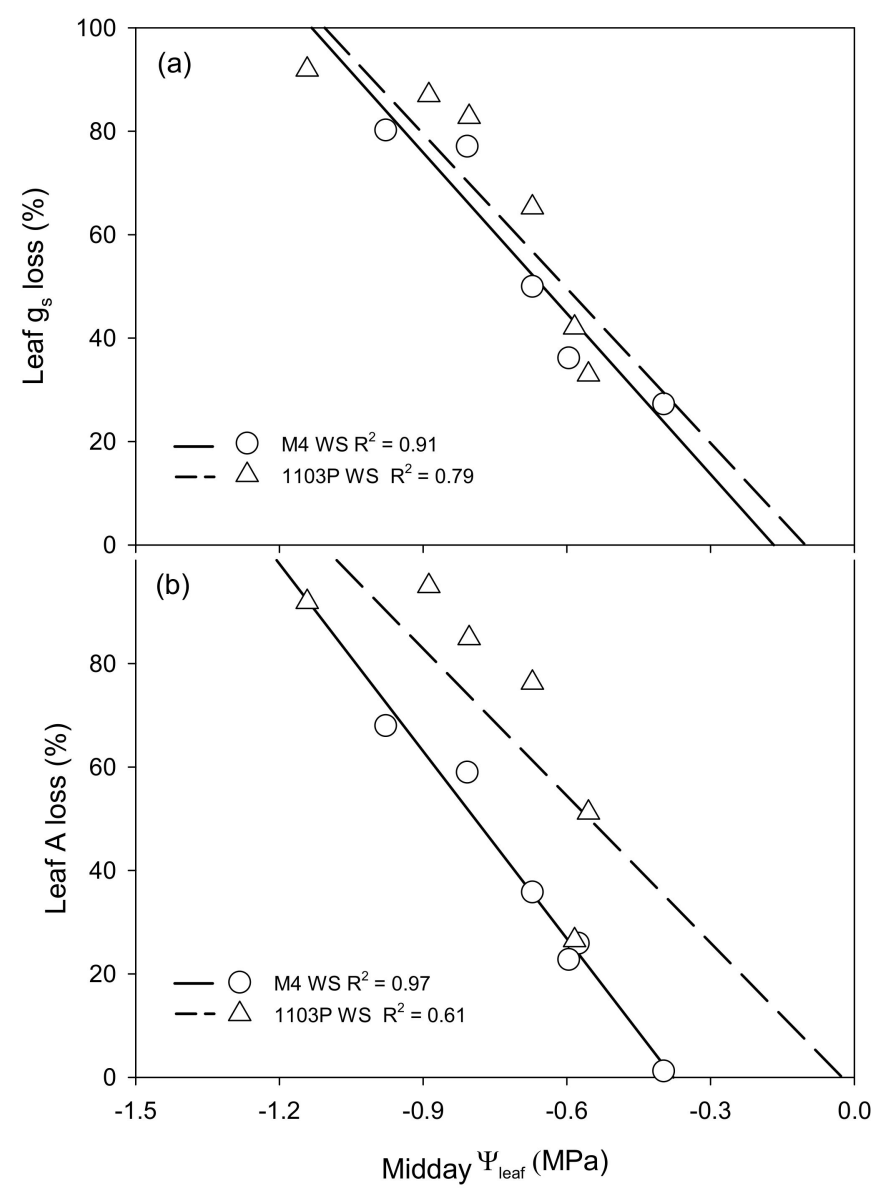

Figure 4. Panel (a) — correlation between midday leaf water potential (Midday $\Psi_{\text {leaf }}$ ) and fraction of leaf stomatal conductance loss (Leaf $g_{s}$ loss). Panel (b) - correlation between Midday $\Psi_{\text {leaf }}$ and fraction of leaf assimilation rate loss (Leaf A loss). M4-WS = water-stressed vines grafted to M4 (panel a: $\mathrm{y}=-103.66 \mathrm{x}-17.41, R^{2}=0.91, p<0.05$; panel b: $\mathrm{y}=-120.76 \mathrm{x}-45.61, R^{2}=0.97, p<0.05$ ); $1103 \mathrm{P}-\mathrm{WS}=$ water-stressed vines grafted to $1103 \mathrm{P}$ (panel a: $\mathrm{y}=-99.66 \mathrm{x}-10.16, R^{2}=0.79, p<0.05$; panel b: $\left.y=-94.76 x-2.39, R^{2}=0.61, p<0.05\right)$.

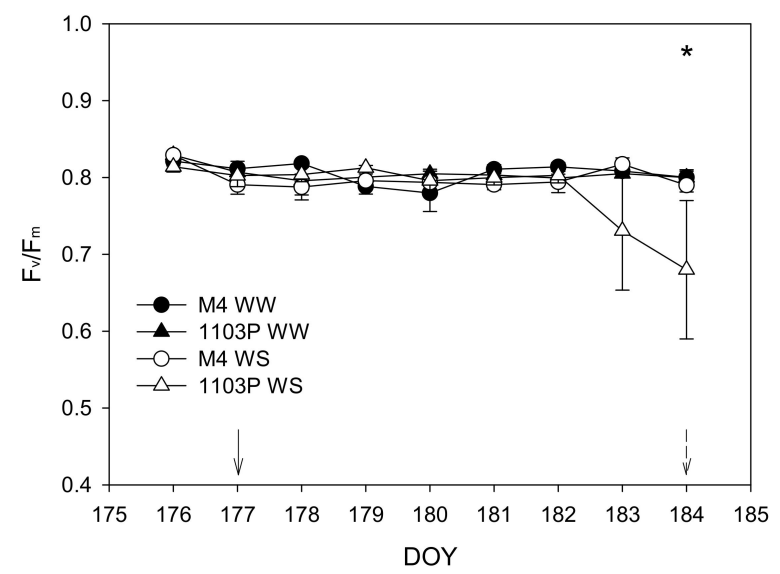

Figure 5. Trends for leaf chlorophylls fluorescence parameter $\left(\mathrm{F}_{\mathrm{v}} / \mathrm{F}_{\mathrm{m}}\right)$ of Grechetto Gentile vines grafted to M4 and 1103P. M4-WW = well-watered vines/M4; 1103P-WW = well-watered vines/1103P; M4-WS = water-stressed vines/M4; 1103P-WS = water-stressed vines/1103 Paulsen; DOY = day of the year. Bars represent standard errors $(n=5)$. Asterisk indicates dates within which significant differences among treatments were found, according to the SNK test $(p<0.05)$. Solid arrow indicates date of imposition of WS; dashed arrow indicates date of re-watering. 
When the experiment ended, either water supply or rootstock (Table S1) was not found to affect vine leaf area, and this held true for both primary and lateral components. In addition, the lateral shoot leaf area was found to be marginally higher as compared to the leaf area of main shoots, irrespective of the treatment.

\section{Discussion}

In fully irrigated vines, higher water use from vines grafted on 1103P was quite apparent. It was assessed during the dry down period on both a daily and diurnal basis (DOY 183) and also confirmed upon re-watering (DOY 184). Of course, water use should take into account either transpiration per unit leaf area and the amount of leaf area. It is well known that rootstocks can easily confer different vigor to the grafted scion [12,31]; in our study, though, vegetative growth parameters (Table S1) show that, albeit 1103P had a tendency to slightly push growth, no significant difference was found in vine leaf area at the end of the experiment, therefore re-enforcing the reliability of single leaf readings. A very recent paper by Dayer et al. [19] had examined changes of key drought-tolerance traits in three cultivars (Grenache, Shiraz, and Semillon) that have largely contrasting water use behavior. Interestingly, they found that the maximum E rate measured under well-watered conditions also affected the variation of a number of drought indices upon progressive water stress. For instance, it was found that increasing maximum E correlated with a lower sensitivity of stomatal conductance to VPD and also with more negative water potential at which stomata close. Transposing these effects to our study only yielded a partial matching. Indeed, higher water used recorded in 1103P-WW vines might have caused faster soil water depletion than in M4, hence also explaining the less rapid decline in pre-dawn and midday leaf water potential. Conversely, in both rootstocks, leaf $\mathrm{E}$ rates had a quite similar variation vs. increasing air VPD (not shown) and the same occurred for the $\Psi_{\text {leaf }}$ threshold at which stomatal closure occurred (only $-0.03 \mathrm{MPa}$ difference between the two rootstocks vs. about $0.4 \mathrm{MPa}$ difference between Semillon and Grenache according to Dayer et al. [19]). Thus, it does appear that in our study, grafting Grechetto Gentile vines on either 1103P and M4 did not significantly change the rather conservative behavior of the variety under progressive drought.

However, while the linear model describing the reduction of leaf $g_{s} v s$. decreasing $\Psi_{\text {leaf }}$ shared similar slopes and intercepts between the rootstocks (Figure 4a), when leaf A was taken into account, the linear model fit to the two rootstock data groups still featured the same slope, but the intercept was different (Figure $4 \mathrm{~b}$ ). Derived conclusions are that, at any given $\Psi_{\text {leaf }}$, grafting vines on M4 achieves a $15 \%$ less limited leaf A, or, reading it the other way, in M4, the $\Psi_{\text {leaf }}$ threshold at which leaf A gets severely limited is reached later in the season.

Meggio et al. [7], who made a comparison between own-rooted M4 and own-rooted 101-14 Millardet et De Grasset vines, reported higher leaf $g_{s}$ and leaf A by M4 amidst lower supply of water. SO4 and 101-14 Millardet et De Grasset are classified as weak rootstocks with a low tolerance to water stress [12-15]. The novelty of our work is that better performance induced by M4 under moderate-to-severe water stress is also confirmed vs. a drought-tolerant rootstock such as 1103P, therefore broadening its scale of applicability.

Indeed, when it comes to explaining through which mechanisms M4 is able to maintain better leaf function under water stress as compared to other rootstocks, the scenario is still fuzzy. In their experiment on own-rooted potted M4 vines, Meggio et al. hypothesized active osmotic adjustment that was not seen in the commercial rootstock 101.14; from the transcriptomic side, Corso et al. [16] showed that water-stressed own-rooted M4 vines had higher expression of VsSTS genes coding for resveratrol and flavonoid biosynthesis. The proposed mechanism was that elevated synthesis of resveratrol in M4 roots upon water stress might enhance the ability to cope with oxidative stress usually associated with water deficit [32]. The last hypothesis has a link with what we found in our work as M4 contributed to counteract photochemical damages to Photosystem 2 under severe WS, as it avoided the permanent reduction of Fv/Fm that was instead recorded in 1103P-WS (Figure 5). 
Differential response of leaf water status and photosynthesis recorded in the two rootstocks translates into higher $\mathrm{WUE}_{\text {leaf }}$ under drought for M4. Having a rootstock that can improve WUE $\mathrm{E}_{\text {leaf }}$ of the grafted scion at moderate to severe water stress levels is very relevant especially in areas where the frequency of significant summer drought is dramatically increasing due to global warming impact. Paradoxically, in the same areas, irrigation is not usually available due to water scarcity or even forbidden due to law-enforced yield limitation. Under such circumstances and in the impossibility of implementing any irrigation strategy, a rootstock that can even slightly enhance vine resilience to water stress by warranting that leaf disruption due to either irreversible photo-inhibition and/or embolism is somewhat postponed is a key factor. In a previous paper from Galbignani et al. [8], it was shown that whole-canopy water use efficiency was significantly increased in water-stressed potted Sangiovese vines grafted on $\mathrm{M} 4$ vs. stressed $\mathrm{SO} 4$ when water supply was reduced to $50 \%$ and $30 \%$ of water lost by the respective well-watered controls. It could be argued that in the present work, we measured $W_{U E}$ leaf and that, according to literature, the methodology used (i.e., measures taken on single leaves held perpendicular to the sun or under their natural position or directly on the whole canopy) can lead to different conclusions about $W E_{\text {leaf }}$ variation under water stress [29,33,34]. Medrano et al. [33] and Poni et al. [34] have shown, though, that possible mismatch between single leaf or whole canopy derived measurements of $W_{U E} E_{\text {leaf }}$ worsens when the whole canopy encompasses large leaf areas and a complex leaf population generating high within-canopy variability in terms leaf age, exposure, and health. This is not the case of our study, where the canopy was given by two vertically growing shoots, in all cases well-exposed to light. Such a simplified canopy makes it very likely that the estimated single $W_{U E}$ leaf is a good proxy of vine behavior.

Rootstock-induced tolerance to water stress should not be regarded only in terms of maintenance of functionality during a water shortage, rather also as a capacity to induce a prompter resumption of canopy function once non-limiting water availability is replenished in the soil. According to Meggio et al. [7], own-rooted M4 vines boast a higher leaf A as compared to commercial rootstocks at the restoration of water supply, following the WS period. In our trial, physiological resumption of M4 and 1103P in comparison to the respective WW treatments revealed that M4-WS more promptly recovered leaf gas exchange rates after the complete restoration of water supply. This is another interesting feature of resilience to water stress conferred by the M4 which, quite likely, relates to no significant photo-inhibition experienced by M4 leaves at severe stress.

\section{Conclusions}

The hypothesis made in our work was centered around the possibility that the rather conservative water use behavior of cv. Grechetto Gentile vines could be improved when grafted on the new M4 rootstock, as compared to the drought-tolerant 1103P. The assessment was made through a fast-dry down-cycle followed by re-watering. Although higher water use ascertained in 1103P-WW vines likely accelerated soil water depletion, the dynamic of stomatal limitation to water loss as a function of a decreasing leaf water potential was not greatly affected since stomatal closure was reached at very similar $\Psi_{\text {leaf }}$ (about $-1.1 \mathrm{MPa}$ ). Despite such similarity in leaf water status traits, M4 enhanced leaf photosynthesis performance under multiple sides: (i) lower leaf A reduction at similar $\Psi_{\text {leaf }}$, (ii) increased leaf $A$ and $W_{U E}$ leaf at the peak of water stress, (iii) lower photo-inhibition and prompter leaf A recovery upon re-watering.

Taking these factors together, M4 confirms the ability to improve scion's performance even when compared to a drought-tolerant rootstock and stands as an important factor of resilience to water stress, especially when environmental drought combines with water scarcity, rendering the recourse to irrigation impossible or unsustainable. 
Supplementary Materials: The following are available online at http://www.mdpi.com/2073-4395/10/5/708/s1. Figure S1: Hourly trends of air temperature $(\mathrm{T})$, and relative humidity $(\mathrm{RH})$ and daily trend of air vapor pressure deficit (VPD) and rainfall recorded at the experimental site over the trial period. The arrows indicate the first day of water stress imposition (WS) and the date of re-watering (RW). Figure S2: Daily trend for leaf stomatal conductance $\left(\mathrm{g}_{\mathrm{s}}\right)$ of vines cv. Grechetto Gentile grafted to M4 and 1103 Paulsen. M4-WW = well-watered vines grafted to M4; 1103P-WW = well-watered vines grafted to 1103 Paulsen; M4-WS = water-stressed vines grafted to M4; 1103P-WS = water-stressed vines grafted to 1103 Paulsen; DOY = day of the year. Bars represent standard errors $(n=5)$. Asterisk indicates dates within which significant differences among treatments were found according to SNK test $(p<0.05)$. Solid arrow indicates date of imposition of WS, dashed arrow indicates date of re-watering. Table S1: Leaf area from primary and lateral shoots of vines cv. Grechetto Gentile grafted to M4 and 1103 Paulsen. M4-WW = well-watered vines grafted to M4; 1103P-WW = well-watered vines grafted to 1103 Paulsen; M4-WS = water-stressed vines grafted to M4; 1103P-WS = water-stressed vines grafted to 1103 Paulsen; DOY = day of the year.

Author Contributions: Conceptualization, T.F., S.T., and S.P.; data curation, T.F., A.B., and C.S.; formal analysis, S.T. and S.P.; funding acquisition, M.G. and S.P.; investigation, T.F., A.B., C.S., and S.P.; methodology, T.F., A.B., C.S., S.T., M.G., and S.P.; project administration, S.P.; resources, S.P.; supervision, S.P.; writing-original draft, T.F. and S.P.; writing-review and editing, C.S., S.T., and M.G. All authors have read and agreed to the published version of the manuscript.

Funding: This study was funded within the GENBACCA project (grant No. 728079 POR-FESR 2014-2020, Regione Emilia-Romagna).

Conflicts of Interest: The authors declare no conflict of interest.

\section{References}

1. Palliotti, A.; Tombesi, S.; Silvestroni, O.; Lanari, V.; Gatti, M.; Poni, S. Changes in vineyard establishment and canopy management urged by earlier climate-related grape ripening: A review. Sci. Hortic. 2014, 178, 43-54. [CrossRef]

2. Jones, G.V.; White, M.A.; Cooper, O.R.; Storchmann, K. Climate change and global wine quality. Clim. Chang. 2005, 73, 319-343. [CrossRef]

3. Jones, G.V. Climate, grapes, and wine: Structure and suitability in a changing climate. Acta Hortic. 2012, 931, 19-28. [CrossRef]

4. Duchêne, E.; Schneider, C. Grapevine and climatic changes: A glance at the situation in Alsace. Agron. Sustain. Dev. 2005, 25, 93-99. [CrossRef]

5. Van Leeuwen, C.; Destrac-Irvine, A.; Dubernet, M.; Duchêne, E.; Gowdy, M.; Marguerit, E.; Pieri, P.; Parker, A.; de Rességuier, L.; Ollat, N. An Update on the Impact of Climate Change in Viticulture and Potential Adaptations. Agronomy 2019, 9, 514. [CrossRef]

6. Poni, S.; Gatti, M.; Palliotti, A.; Dai, Z.; Duchêne, E.; Truong, T.T.; Ferrara, G.; Matarrese, A.M.S.; Gallotta, A.; Bellincontro, A.; et al. Grapevine quality: A multiple choice issue. Sci. Hortic. 2018, 234, 445-462. [CrossRef]

7. Meggio, F.; Prinsi, B.; Negri, A.S.; Simone Di Lorenzo, G.; Lucchini, G.; Pitacco, A.; Failla, O.; Scienza, A.; Cocucci, M.; Espen, L. Biochemical and physiological responses of two grapevine rootstock genotypes to drought and salt treatments. Aust. J. Grape Wine Res. 2014, 20, 310-323. [CrossRef]

8. Galbignani, M.; Merli, M.C.; Magnanini, E.; Bernizzoni, F.; Talaverano, I.; Gatti, M.; Tombesi, S.; Palliotti, A.; Poni, S. Gas exchange and water-use efficiency of cv. Sangiovese grafted to rootstocks of varying water-deficit tolerance. Irrig. Sci. 2016, 34, 105-116. [CrossRef]

9. Merli, M.C.; Magnanini, E.; Gatti, M.; Pirez, F.J.; Pueyo, I.B.; Intrigliolo, D.S.; Poni, S. Water stress improves whole-canopy water use efficiency and berry composition of cv. Sangiovese (Vitis vinifera L.) grapevines grafted on the new drought-tolerant rootstock M4. Agric. Water Manag. 2016, 169, 106-114. [CrossRef]

10. Corso, M.; Vannozzi, A.; Maza, E.; Vitulo, N.; Meggio, F.; Pitacco, A.; Telatin, A.; D’Angelo, M.; Feltrin, E.; Negri, A.S.; et al. Comprehensive transcript profiling of two grapevine rootstock genotypes contrasting in drought susceptibility links the phenylpropanoid pathway to enhanced tolerance. J. Exp. Bot. 2015, 66, 5739-5752. [CrossRef]

11. Prinsi, B.; Negri, A.S.; Failla, O.; Scienza, A.; Espen, L. Root proteomic and metabolic analyses reveal specific responses to drought stress in differently tolerant grapevine rootstocks. BMC Plant Biol. 2018, 18, 126. [CrossRef] [PubMed]

12. Serra, I.; Strever, A.; Myburgh, P.A.; Deloire, A. The interaction between rootstocks and cultivars (Vitis vinifera L.) to enhance drought tolerance in grapevine. Aust. J. Grape Wine Res. 2014, 20, 1-14. [CrossRef] 
13. Carbonneau, A. The early selection of grapevine rootstocks for resistance to drought conditions. Am. J. Enol. Vitic. 1985, 36, 195-198.

14. Corso, M.; Bonghi, C. Grapevine rootstock effects on abiotic stress tolerance. Plant Sci. Today 2014, 1, $108-113$. [CrossRef]

15. Smart, D.R.; Schwass, E.; Lakso, A.; Morano, L. Grapevine rooting patterns: A comprehensive analysis and a review. Am. J. Enol. Vitic. 2006, 57, 89-104.

16. Corso, M.; Vannozzi, A.; Ziliotto, F.; Zouine, M.; Maza, E.; Nicolato, T.; Vitulo, N.; Meggio, F.; Valle, G.; Bouzayen, M.; et al. Grapevine rootstocks differentially affect the rate of ripening and modulate auxin-related genes in Cabernet Sauvignon berries. Front. Plant Sci. 2016, 7, 69. [CrossRef]

17. Berger-Landefeldt, U. Der Wasserhaushalt der Alpenpflanzen; Schweizerbart Science Publishers: Stuttgart, Germany, 1936.

18. Hochberg, U.; Rockwell, F.E.; Holbrook, N.M.; Cochard, H. Iso/anisohydry: A plant-environment interaction rather than a simple hydraulic trait. Trends Plant Sci. 2018, 23, 112-120. [CrossRef]

19. Dayer, S.; Herrera, J.C.; Zhanwu, D.; Burlett, R.; Lamarque, L.J.; Delzon, S.; Bortolami, G.; Cochard, H.; Gambetta, G. The sequence and thresholds of leaf hydraulic traits underlying grapevine varietal differences in drought tolerance. J. Exp. Bot. 2020. [CrossRef]

20. Ratzmann, G.; Meinzer, F.C.; Tietjen, B. Iso/Anisohydry: Still a Useful Concept. Trends Plant Sci. 2019, 24, 191-194. [CrossRef]

21. Tardieu, F.; Simmoneau, T. Variability among species of stomatal control under fluctuating soil water status and evaporative demand: Modelling isohydric and anisohydric behaviours. J. Exp. Bot. 1998, 49, 419-432. [CrossRef]

22. Pou, A.; Medrano, H.; Tòmas, M.; Martorell, S.; Ribas-Carbò, M.; Flexas, J. Anisohydric behaviour in grapevines results in better performance under moderate water stress and recovery than isohydric behaviour. Plant Soil 2012, 359, 335-349. [CrossRef]

23. Palliotti, A.; Tombesi, S.; Frioni, T.; Famiani, F.; Silvestroni, O.; Zamboni, M.; Poni, S. Morpho-structural and physiological response of container-grown Sangiovese and Montepulciano cvv. (Vitis vinifera) to re-watering after a pre-veraison limiting water deficit. Funct. Plant Boil. 2014, 41, 634-647. [CrossRef]

24. Sade, N.; Gebremedhin, A.; Moshelion, M. Risk-taking plants: Anisohydric behavior as a stress-resistance trait. Plant Signal Behav. 2012, 7, 767-770. [CrossRef] [PubMed]

25. Schultz, H.R. Differences in hydraulic architecture account for near-isohydric and anisohydric behaviour of two field-grown Vitis vinifera L. cultivars during drought. Plant Cell Environ. 2003, 26, 1393-1405. [CrossRef]

26. Palliotti, A.; Poni, S.; Silvestroni, O.; Tombesi, S.; Bernizzoni, F. Morpho-structural and physiological performance of Sangiovese and Montepulciano cvv. (Vitis vinifera) under non-limiting water supply conditions. Funct. Plant Boil. 2011, 38, 888-898. [CrossRef]

27. Hochberg, U.; Bonel, A.G.; David-Schwartz, R.; Degu, A.; Fait, A.; Cochard, H.; Peterlunger, E.; Herrera, J.C. Grapevine acclimation to water deficit: The adjustment of stomatal and hydraulic conductance differs from petiole embolism vulnerability. Planta 2017, 245, 1091-1104. [CrossRef]

28. Chaves, M.M.; Zarrouk, O.; Francisco, R.; Costa, J.M.; Santos, T.; Regalado, A.P.; Rodrigues, M.L.; Lopes, C.M. Grapevine under deficit irrigation: Hints from physiological and molecular data. Ann. Bot. 2010, 105, 661-676. [CrossRef]

29. Palliotti, A.; Poni, S. Grapevine under light and heat stresses. In Grapevine in a Changing Environment: A Molecular and Ecophysiological Perspective; Wiley \& Sons Inc.: Hoboken, NJ, USA, 2016; pp. 148-178.

30. McCutchan, H.; Shackel, K.A. Stem-water potential as a sensitive indicator of water stress in prune trees (Prunus domestica L. cv. French). J. Am. Soc. Hortic. Sci. 1992, 117, 607-611. [CrossRef]

31. Marguerit, E.; Brendel, O.; Lebon, E.; Van Leeuwen, C.; Ollat, N. Rootstock control of scion transpiration and its acclimation to water deficit are controlled by different genes. New Phytol. 2012, 194, 416-429. [CrossRef]

32. Palliotti, A.; Tombesi, S.; Frioni, T.; Silvestroni, O.; Lanari, V.; D’Onofrio, C.; Matarese, F.; Bellincontro, A.; Poni, S. Physiological parameters and protective energy dissipation mechanisms expressed in the leaves of two Vitis vinifera L. genotypes under multiple summer stresses. J. Plant Physiol. 2016, 185, 84-92. 
33. Medrano, H.; Tomás, M.; Martorell, S.; Flexas, J.; Hernández, E.; Rosselló, J.; Pou, A.; Escalona, J.M.; Bota, J. From leaf to whole-plant water use efficiency (WUE) in complex canopies: Limitations of leaf WUE as a selection target. Crop J. 2015, 3, 220-228. [CrossRef]

34. Poni, S.; Bernizzoni, F.; Civardi, S.; Gatti, M.; Porro, D.; Camin, F. Performance and water-use efficiency (single-leaf vs. whole-canopy) of well-watered and half-stressed split-root Lambrusco grapevines grown in Po Valley (Italy). Agric. Ecosyst. Environ. 2009, 129, 97-106. [CrossRef] 